\title{
ОРГАНИЗАЦИОННОЕ СОПРОВОЖДЕНИЕ ГОСУДАРСТВЕННЫХ ЗЕЛЁНЫХ ЗАКУПОК В РОССИИ. ФОРМИРОВАНИЕ РЫНКА ЭКОЛОГИЧНЫХ ТОВАРОВ
}

\section{(c) 2019 Сметанина Татьяна Петровна}

кандидат экономических наук, ведущий научный сотрудник научно-исследовательской лаборатории «Исследования актуальных вопросов развития конкурентной политики и государственного заказа в российской экономике» Центра развития конкурентной политики и государственного заказа

Российская академия народного хозяйства и государственной службы при Президенте Российской Федерации, Россия, Москва

E-mail: smetanina.tatiana@gmail.com

В статье представлены предложения, связанные с практическими действиями по управленческому сопровождению формирования рынка экологичных товаров. Рассмотрена необходимость целевого анализа текущего состояния рынка на предмет наличия количества и качества сертифицированных товаров и услуг, способы формирования каталогов «зеленой» продукции, учета и верификации экологической маркировки и систем сертификации, обозначена необходимость проведения пилотных торгов с целью дальнейшего анализа и продвижения новой технологии. Обозначена также необходимость институционального определения исполнителей работ по формированию экологических критериев продукции, значение информационной и просветительской деятельности. Представлена структурная основа для формирования государственной программы в области зеленых закупок.

Ключевые слова: рынок экологичных товаров, экологическая сертификация, зеленые государственные закупки, каталоги экологичных товаров, национальный план действия в области зеленых закупок, экологическое просвещение

Анализ товарного отраслевого рынка

Для того, чтобы иметь четкое представление об отправных направлениях систематизации и перспективного формирования рынка экологичных товаров, нужно, пользуясь статистическими агрегаторами и другими доступными данными, составить текущую картину наличия на отраслевых национальных рынках «зеленой» продукции, как отечественной, так и зарубежной. Необходимо иметь в российском масштабе информацию о присутствующей здесь же в долевом отношении эко-маркировке, ее уровне, характере и продуктивности сертифицирующих организаций.

Следующим этапом агрегации и обработки данных должен стать пункт методической оценки работы сертифицирующих организаций с привлечением общественных организаций. Проверочная работа должна акцентировать внимание на конкретных объектах сертификации методом случайной выборки, имея цель осветить как лучшие, так и негативные практики соответствующих структур с последующим формированием публичного открытого рейтинга сертифицирующих организаций с включением системы оценки через специализированные IT порталы с применением протокола подтверждения.

Данная работа представляется целесообразной в силу масштабного лукавства, имеющего место на рынке сертификации, а также для оценки долевого вклада сертифицирующих организаций в создание/появление/фиксации («брендировании») эко-товаров на отраслевом рынке. Разобраться в этой области принципиально необходимо, чтобы «отделить зерна от плевел», обеспечить здоровую подконтрольность общей политике экологической сертификации и предпринять дальнейшие шаги в продвижении реальной эко-маркировки.

Упомянутое соотношение эко-товаров в общей массе отраслевых товаров полезно рассмотреть в динамике периода от пяти лет, чтобы понять сложившиеся тенденции и роль основных участников «игрового поля», включая производителей, потребителей, сертифицирующие организации, контролирующие органы и т.д. Здесь важны и масштабы работы тех или иных участ- 
ников.

Демократичная ревизия поможет плавно перейти к стадии планирования работы по экологическим критериям в госзакупках, так как оцененные организационные и брендовые возможности работающей сертификации должны быть учтены в их формировании. Это немаловажно, так как национальный рынок имеет особенности управления, и продуманный методический подход может принести очевидную пользу обществу через последовательное внедрение современных технологичных систем независимого автоматизированного контроля.

Каталоги экологичной продукции

В первой части нашей работы мы уже уделили внимание Европейскому каталогу экологичных товаров [1] и упоминали российский проект Green Book [2], поддержанный Правительством РФ и находящийся в координации EcoStandard group. Green Book аккумулирует на настоящий момент информацию по строительным материалам и строительной отрасли в целом, а Европейский каталог предоставляет актуальные сведения по следующим отраслям: одежда и текстиль, покрытия, лаки и краски, электронное оборудование, мебель, садоводство (включительно удобрения и мульча), бытовая техника (тепловые насосы, водонагреватели), смазочные материалы (разнообразные масла и консистентные смазки), предметы домашнего обихода, бумажные изделия, средства личной гигиены. Работа продолжается и расширяется по отраслям. Европейская комиссия заявляет, что каждый владелец экологической лицензии должен зарегистрировать свой продукт в Каталоге, пользуясь предоставляемой инструкцией, и подчеркивает официально эту обязанность держателей лицензий, потому что предоставляемая «база данных может быть не исчерпывающим списком». Для компаний открыто Руководство пользователя ECAT/ ECAT User Manuals for Licence Holders [3] (для держателей лицензий), которое доступно на всех языках ЕC, а пользователь управляет своей учетной записью через соответствующую регистрацию в системе. Для получения помощи компании могут обратиться в специализированную справочную службу Ecolabel EC - EU Ecolabel Helpdesk.

На что целесообразно обратить внимание - это масштаб проводимой работы. В этом отношении, обосновывая рекомендации для формирования профильного каталога, можно рассчитывать на соответствующий эффект в случае смещения акцента данной деятельности с частных площадок (-ки) на государственный уровень. Как представляется, блок ключевых задач и их исполнение в структурном управлении устойчивым экономическим развитием должен принадлежать государству. Исходя из опыта успешной работы Европейской Комиссии в названном направлении, Правительство Российской Федерации должно иметь в своем составе соответствующие институциональные единицы, которым должно поручить решение вопросов формирования отраслевых каталогов, ведение учета и работу с держателями лицензий и самими лицензиарами (здесь тоже государственная задача должна быть масштабирована).

Очень важный вопрос - обеспечение максимальной независимости систем экологической маркировки/сертификации, где идеальный вариант функционирования состоит в самофинансировании лицензиара, опирающегося на оплату за право использования экологической маркировки. Можно принять к сведению, например, целесообразность привязки объема платежа за право использования полученного знака к товарообороту отраслевого продукта.

Так как экологический знак присваивается продуктам, а не технологиям или предприятию (принцип маркировки), речь должна идти о конечном продукте, готовом к потреблению. Как мы уже упоминали, важно наличие существующего отраслевого товарного рынка сбыта. Из этого следует, что цель должна состоять не в количестве присваиваемых экологических знаков в единицу времени, а в пользе и целесообразности его практического применения, в первую очередь в продуктовых группах, позволяющих снизить негативное воздействие на окружающую среду. Речь идет о содержании опасных веществ, вредных выбросах и сбросах в воду и почвы, шумовых нагрузках, образовании отходов, использовании невозобновляемых видов сырьевых ресурсов. Эколого-экономический анализ должен охватить весь жизненный цикл продукта, включая конечную стадию утилизации и переработки.

Важный вопрос состоит в установлении продолжительности действия полученной экологической маркировки и праве на ее присутствие в каталоге экологичных продуктов. Упомянутое ограничение связано с активными изменениями в технологии и ситуации на действующем 
рынке; технологический прогресс с течением времени неумолимо ускоряется, поэтому целесообразно ограничение срока действия полученного экологического бренда в пределах нескольких лет (точный срок зависит от отрасли и особенностей продукта). Возможно, эти сроки будут со временем сокращаться. В таком случае технологически изменится и сама система сертификации, она, по определению, станет проще по доступности, исполнению и во многом автоматизирована.

В Экспертном совете по присвоению эко-маркировки (жюри) структурно должны быть задействованы представители ведущих государственных институтов, функционально связанных вопросами охраны природы: Росприроднадзора, Госстандарта России, Торгово-промышленной палаты Российской Федерации, санитарно-эпидемиологического надзора, общественных экологических организаций, Общества потребителей и других заинтересованных сторон.

Разграничение функций между разными органами системы экологической сертификации следует методически подробно описать и открыть для размещения на соответствующем сайте. Информация, как мы уже акцентировали, должна быть понятна и максимально доступна претендентам на эко-маркировку, которые при поддержке портала должны получать бесплатные консультации в случае возникновения затруднений. Национальная система экологической сертификации должна быть выверена на предмет гармонизации с международной практикой.

Сертифицирующие органы/организации должны соблюдать принцип своей независимости от действующих сторон. Отдельные принципиальные моменты, об обеспечении прозрачности которых стоит подумать, касаются вопросов аккредитации органов по эко-сертификации, специализированных аналитических лабораторий, квалификации/аттестации и подготовки экспертов. Государству следует сосредоточиться на обеспечении информационных, методических и консалтинговых услуг для поддержки корректной деятельности сертифицирующей отрасли, с целью облегчения ее доступности, простоты и прозрачности на основе современных электронных технологий. Как часть системы, должна быть освещена цепочка необходимых действий по взаимному признанию органами сертификации знаков соответствия, сертификатов и результатов лабораторных испытаний на договорной основе. Разработка нормативно-методической документации, ее экспертиза, ведение строгого детального реестра, гармонизация деятельности с международными и национальными системами сертификации, квалифицированный инспекционный контроль - все это может действенно помочь формированию рациональной системы экологической сертификации, и, соответственно, качеству использования эко-критериев в закупочном процессе, достоверному отражению полезной информации в каталогах продукции.

Формирование рынка экологичных товаров

Практика применения зеленых/экологических критериев вызовет ответную реакцию рынка. Поставщикам придется принять к учету требования государственных закупщиков, перестраивая характер производства. Ясно, что гладким и бесспорным этот процесс враз не станет, но, тем не менее, следуя мировым тенденциям, нам придется его запустить.

Еще раз стремимся подчеркнуть важный момент, который заключается в создании соответствующей правовой и нормативно-организационной базы, методического сопровождения, доступ к которому должен быть открыт для заинтересованных пользователей. Подготовленная организационная база для опосредования в закупочном процессе должна служить одновременно консультативно-методической площадкой для сторон, вовлеченных в закупочный процесс, с равными правами по доступу и обслуживанию вне зависимости от региона и масштаба действия.

\section{Эксперимент}

Целесообразно инициировать и провести добровольный основе первичный эксперимент по включению эко-критериев в обязательные закупочные требования, на основе имеющихся экологических стандартов. При этом надо иметь ввиду, что готовности номер один у российского рынка сейчас нет, есть вопросы к системам экологической сертификации, нет доверия к предоставляемой документации, а сам производитель в массовой части не готов ответить выставляемым требованиям, парируя требования аргументом о длительной временной перестройке производства и отсутствии соответствующего финансирования. Тем не менее, прецедент нужно создать, выборочные торги с учетом мини- 
мальных для начала экологических требований провести, с расчетом осветить эту практику в средствах массовой информации, анализируя и синтезируя полученный опыт, и поднимая его на новый уровень. Нужно учесть и опыт Правительства Москвы, и строительства спортивных объектов Олимпиады, осветив публично полезную для потребителя информацию по применению вариантов экологических критериев.

\section{Исполнители}

Работу по формированию экологических критериев, как уже говорилось, следует поручить научному, в идеале специализированному институту, одновременно выполняя государственно важную задачу поддержки, положительного пиара и распространения опыта компаний, практикующих наилучшие доступные технологии, продукция которых соответствует зеленым стандартам, вне зависимости от вида собственности и, хотелось бы (в идеале), от страны-производителя. Здесь нужно оговориться, что российский товарный рынок очень многонационален по продукции, представленной на нем. В этом смысле общий рейтинг «зеленых» компаний был бы очень кстати, учитывая доступность «устойчивой» отчетности по международным формам. Разумеется, интерес российского производителя должен быть учтен, но следует допускать также разумную конкуренцию, помогая при этом отечественным предприятиям учиться развивать, документально подтверждать, анонсировать и защищать свои преимущества (не только экологического характера).

Нужно отметить важность грамотного руководства в области формирования экологических критериев продукции. В этой связи, опираясь на европейский опыт, мы предложили бы сформировать Экспертную консультативную группу по зеленым закупкам в составе представителей регионов, Торгово-промышленной палаты РФ, Ассоциации малых и средних предприятий, общественных природоохранных организаций, Общества потребителей, и, возможHo, ICLEI-представителей (либо представителей профильных организаций) для проведения/предоставления консультаций с Правительством РФ по разработке и реализации политики зеленых закупок, конкретизации плана действий. Такая группа может собираться два раза в год (или чаще по необходимости) с утвержденной и согласованной в рабочем порядке повесткой работы.

\section{Информация и просвещение}

Информационная тема должна быть ведущей на пути построения системы экологичных закупок. В настоящее время с понимаем в этой части мы видим большие проблемы. Разговоры о соответствующих системах обучения остаются в большей части, благим пожеланием. Имеющиеся образовательные курсы экологических факультетов и ВУЗов, касающиеся «зеленой» тематики, имеют зачастую узкоспециализированный, технологический характер, а точечный опыт чтения обзорных курсов по «Зеленой экономике» оставляет закупочные вопросы, связанные с эко-критериями, без внимания.

Поэтому следует создать соответствующие учебные курсы на базе Министерства природных ресурсов и экологии РФ, так же и на базе Правительства Москвы, постепенно распространяя этот опыт на регионы. С точки зрения общественной пользы было бы рационально обязать менеджмент высшего уровня пройти обязательное кратковременное обучение (с учетом занятости слушателей), чтобы ознакомить чиновников с практическим инструментарием экологизации экономики и мировыми тенденциями в закупочной деятельности. Следует добиться того, чтобы руководители соответствующих уровней понимали, что такое цикличная экономика и экологические критерии продукции, и то, насколько это важно для нашей общей жизни, будущего детей в внуков, вне зависимости от локализации места жительства и материального статуса.

Расширенный вариант экологической подготовки слушателей могут предоставить экологические факультеты университетов.

Национальный план действий

Перед Правительством России нужно поставить задачу формирования Национального плана действий в области экологичных государственных закупок в координации с основными торговыми партнерами. План должен предусматривать схему движения по отраслевым приоритетам как в разработке критериев/требований к продукции, так и предусматривать временную и смысловую структуру наращивания потенциала в реализации стратегии устойчивых закупок. Собственно, план, как таковой, должен структурно аккумулировать предложения, представленные выше. Основной его задачей должно стать формирование экологических критериев по отраслям, их методическая поддержка и реа- 
лизация, плановое обучение кадров. Предусмотреть индикативные показатели движения вперед представляется целесообразным, с учетом указания ориентировочных сроков выполнения блока запланированных стратегических действий в отраслевом и территориальном разрезе.

В плане действий должны быть сформирован и учтен организационный график научных мероприятий разного масштаба (федерального и регионального), включая тематические конференции, вебинары и другие, а также отражены принципы формирования, работы и ротации Высшего совета по эко-критериям, актуализированы стадии и структура отраслевой работы по экологическим требованиям к продукции. Методические подходы в оценке продукции, рабочий план по критериям, необходимые условия его формирования/утверждения/использования также должны быть найти место в программ- ных документах. Иллюстрационные примеры правоприменения экологических требований в закупках, выборочные case-study и примеры поисковых систем будут служить большим преимуществом в качестве приложений, дополняющих концепцию предложенных действий.

С целью создания рынка экологичных товаров и услуг политически оформленный документальный посыл в сфере адаптации системы государственных закупок к соответствующим критериям должен включить следующие тематические разделы (табл. 1).

Для обеспечения продуктивности стадийной разработки базовой национальной программы по экологизации зеленых закупок следует организовать тесное взаимодействие перспективных рабочих групп и экспертного ядра с OECD, Европейской комиссией и программой One Planet (Network/The Sustainable

Таблица 1. Базовые структурные разделы для государственной программы зеленых закупок

\begin{tabular}{|c|c|c|}
\hline & Название структурного раздела & Содержание \\
\hline \multirow[t]{6}{*}{1} & \multirow[t]{3}{*}{$\begin{array}{l}\text { Обоснование и представление } \\
\text { потенциальных выгод «зеле- } \\
\text { ных» государственных закупок }\end{array}$} & $\begin{array}{l}\text { Государственные закупки влияют на тенденции производства и } \\
\text { потребления; спрос со стороны государственных органов на эколо- } \\
\text { гичные товары создаст и расширит рынки «чистой» продукции. У } \\
\text { компаний появится к разработке экологических технологий }\end{array}$ \\
\hline & & $\begin{array}{l}\text { Новые технологические разработки помогут поднять конкуренто- } \\
\text { способность России }\end{array}$ \\
\hline & & $\begin{array}{l}\text { Конечная оптимизация государственных издержек с учетом долго- } \\
\text { временного акцента на оценку жизненного цикла товара }\end{array}$ \\
\hline & • Политическая основа & $\begin{array}{l}\text { Соответствие Целям Устойчивого развития ООН, Рекомендациям } \\
\text { ОЭСР, европейскому Плану действий по устойчивому потреблению } \\
\text { и производству и устойчивой промышленной политике (SCP/SIP) }\end{array}$ \\
\hline & • Существующие критерии & $\begin{array}{l}\text { Отраслевые критерии, критерии эко-маркировки, характер крите- } \\
\text { риев, динамические изменения, цели развития }\end{array}$ \\
\hline & $\begin{array}{l}\text { • Барьеры на пути внедрения } \\
\text { эко-критериев/ } \\
\text { Информационные нужды }\end{array}$ & $\begin{array}{l}\text { • недостаток/наличие критериев } \\
\text { • полнота/наличие/отсутствие баз (-ы) данных } \\
\text { • наличие/недостаток информации о стоимости жизненного цикла } \\
\text { продукции и относительных затратах на экологически чистые про- } \\
\text { дукты / услуги } \\
\text { • осведомленность (или ее отсутствие) о преимуществах экологиче- } \\
\text { ски чистых продуктов и услуг } \\
\text { • неопределенность в отношении правовых возможностей включе- } \\
\text { ния экологических критериев в тендерные документы. } \\
\text { • наличие/отсутствие политической поддержки и связанные ресур- } \\
\text { сы для продвижения устойчивых закупок (отдельная статья - целе- } \\
\text { вое обучение, требующая особого внимания } \\
\text { • координация обмена лучшими практиками и многоуровневое } \\
\text { взаимодействие/региональный информационный обмен }\end{array}$ \\
\hline 2 & Цели и задачи & $\begin{array}{l}\text { Ключевые рекомендации по уменьшению воздействия на окружаю- } \\
\text { щую среду, роль государственного сектора, стимулирование инно- } \\
\text { ваций, выявление и устранение барьеров: } \\
\text { • процесс разработки/утверждения/ } \\
\text { гармонизации экологических критериев } \\
\text { • агрегирование информации о стоимости жизненного цикла про- } \\
\text { дуктов } \\
\text { • юридическое и оперативное управление; } \\
\text { • политическая поддержка, индикаторы, мониторинг }\end{array}$ \\
\hline
\end{tabular}




\begin{tabular}{|c|c|c|}
\hline \multirow[t]{4}{*}{3} & \multirow[t]{4}{*}{$\begin{array}{l}\text { Методические подходы и опре- } \\
\text { деления }\end{array}$} & $\begin{array}{l}\text { GPP/определение: это «процесс, посредством которого государ- } \\
\text { ственные органы стремятся обеспечить товары, услуги и работы с } \\
\text { уменьшенным воздействием на окружающую среду на протяжении } \\
\text { всего их жизненного цикла по сравнению с товарами, услугами и } \\
\text { работами с той же основной функцией, которая в противном случае } \\
\text { была бы приобретена» [4] }\end{array}$ \\
\hline & & $\begin{array}{l}\text { Процедуры зеленых закупок (требования к окружающей среде, кри- } \\
\text { терии отбора/назначения, положения о контрактах) }\end{array}$ \\
\hline & & $\begin{array}{l}\text { Экологическая эффективность, преимущества критериев для обе- } \\
\text { спечения конкурентных возможностей }\end{array}$ \\
\hline & & $\begin{array}{l}\text { Варианты критериев (спецификации; критерии экологической } \\
\text { награды - премиальные баллы) + }\end{array}$ \\
\hline \multirow[t]{10}{*}{4} & \multirow[t]{10}{*}{$\begin{array}{l}\text { Критерии и приоритетные } \\
\text { отрасли }\end{array}$} & $\begin{array}{l}\text { Процесс разработки и утверждения критериев: } \\
\text { экомаркировка и аккумуляция информации от заинтересованных } \\
\text { сторон промышленности и гражданского общества как база для } \\
\text { формирования экологических критериев }\end{array}$ \\
\hline & & $\begin{array}{l}\text { Создание экспертной группы (групп)/Открытые стандарты консуль- } \\
\text { тативных процедур и координации одобрения критериев. Позитив- } \\
\text { ный пример доступен здесь [5] }\end{array}$ \\
\hline & & Процедура обсуждения с заинтересованными сторонами \\
\hline & & Регламент утверждения критериев \\
\hline & & $\begin{array}{l}\text { Определение приоритетных секторов" на основе следующих прин- } \\
\text { ципов [4], вариативно: } \\
\text { • возможности для улучшения окружающей среды; } \\
\text { • объем государственных расходов; } \\
\text { • потенциальное воздействие на частных или корпоративных по- } \\
\text { требителей; } \\
\text { • политическая чувствительность; } \\
\text { • возможность применения простых критериев; } \\
\text { • рыночная доступность } \\
\text { • экономическая эффективность }\end{array}$ \\
\hline & & $\begin{array}{l}\text { Опорные источники для формирования критериев: } \\
\text { • Жизненный цикл как основа } \\
\text { • Экологическая маркировка (ведущие и признанные бренды) } \\
\text { • Требования к энергоэффективности (учет контрольных показате- } \\
\text { лей) }\end{array}$ \\
\hline & & $\begin{array}{l}\text { Разделение критериев на общие и продвинутые (с более высокой } \\
\text { эффективностью и амбициями): стимулы для рынка }\end{array}$ \\
\hline & & Система стимулов для непрерывного улучшения критериев \\
\hline & & $\begin{array}{l}\text { Принципы построения критерия для максимизации его простоты и } \\
\text { понимания участниками торгов, а также для необходимой проверки }\end{array}$ \\
\hline & & Установление целевых показателей, бенчмаркетинг и контроль \\
\hline \multirow[t]{4}{*}{5} & \multirow[t]{4}{*}{$\begin{array}{l}\text { Индикаторы для оценки дости- } \\
\text { жения целей }\end{array}$} & $\begin{array}{l}\text { Определение доли закупок, которые могут быть отнесены к «зеле- } \\
\text { ным» согласно применению экологических критериев (по объему/ } \\
\text { доле и времени) }\end{array}$ \\
\hline & & $\begin{array}{l}\text { Предоставить (запланировать) возможность регионам составлять } \\
\text { свои собственные планы эко-закупок согласно возможностям и } \\
\text { амбициям в русле заданной политики. }\end{array}$ \\
\hline & & $\begin{array}{l}\text { Конкретизировать индикативные цели по источникам финанси- } \\
\text { рования целевой работы, включая грантовые, исследовательские } \\
\text { и иные фонды, связанные с политико-экономической и научной } \\
\text { поддержкой }\end{array}$ \\
\hline & & $\begin{array}{l}\text { Расширение учебного блока по зеленым закупкам в общей системе } \\
\text { подготовки сертифицированных закупщиков }\end{array}$ \\
\hline
\end{tabular}

\footnotetext{
* С точки зрения целесообразности начинаний можно взять для начала четыре сектора: строительство (уже в работе/каталоги), общепит, транспорт и энергетический сектор
} 


\begin{tabular}{|c|c|c|}
\hline \multirow[t]{5}{*}{6} & \multirow[t]{5}{*}{$\begin{array}{l}\text { Руководства, рекомендации и } \\
\text { общее регулирование }\end{array}$} & Юридические и операционные руководства \\
\hline & & $\begin{array}{l}\text { Включение политики и процедур «зеленых» закупок в региональ- } \\
\text { ные планы развития с точки зрения развития механизмов и подго- } \\
\text { товки кадров }\end{array}$ \\
\hline & & $\begin{array}{l}\text { Выделение наиболее эффективных вариантов закупочной практики } \\
\text { по эко-критериям с целью освещения подобного опыта в СМИ и } \\
\text { распространения опыта }\end{array}$ \\
\hline & & $\begin{array}{l}\text { Создание федеральной электронной площадки обучения слушате- } \\
\text { лей в работе с эко-критериями с поддержкой региональной работы } \\
\text { в ней }\end{array}$ \\
\hline & & Формирование каталогов экологичной продукции по отраслям \\
\hline \multirow[t]{3}{*}{7} & \multirow[t]{3}{*}{ Стимулирование инноваций } & $\begin{array}{l}\text { Практика предпродажных (предварительных коммерческих) заку- } \\
\text { пок }\end{array}$ \\
\hline & & $\begin{array}{l}\text { Формирование добровольной системы для сторонней проверки } \\
\text { требований к эффективности новых технологий, облегчающей про- } \\
\text { верку соответствия экологическим требованиям, представленных в } \\
\text { тендерной документации }\end{array}$ \\
\hline & & $\begin{array}{l}\text { Выделение отраслевых инновационных рынков, создающих благо- } \\
\text { приятные условия и рамки для развития новых продуктов и услуг, и } \\
\text { стимулы для них }\end{array}$ \\
\hline 8 & $\begin{array}{l}\text { Экологические требования к } \\
\text { продукции в частной закупоч- } \\
\text { ной практике }\end{array}$ & $\begin{array}{l}\text { Методы функциональной связи, методической и оперативной } \\
\text { помощи в реализации принципов устойчивых закупок, укрепление } \\
\text { стимулов взаимодействия в применении эко-критериев }\end{array}$ \\
\hline \multirow[t]{4}{*}{9} & \multirow[t]{4}{*}{$\begin{array}{l}\text { Мониторинг зеленых индика- } \\
\text { торов }\end{array}$} & $\begin{array}{l}\text { • Количественный способ (к примеру: зеленые торги в общей чис- } \\
\text { ленности госзакупок; стоимость зеленых контрактов в общей сумме } \\
\text { государственных контрактов). } \\
\text { • Оценка экологического воздействия/эффекта зеленых закупок } \\
\text { (на основе случайной выборки) }\end{array}$ \\
\hline & & Обеспечение регионального и отраслевого контроля \\
\hline & & $\begin{array}{l}\text { Планирование действий (решение задач и создание стимулов для } \\
\text { инноваций) на основе результатов мониторинга/его эффективности } \\
\text { с точки зрения минимизации воздействия на окружающую среду }\end{array}$ \\
\hline & & $\begin{array}{l}\text { Временной график мониторинга и электронной проверочной вы- } \\
\text { борки* }\end{array}$ \\
\hline
\end{tabular}

* Мониторинг и бенчмаркинг служат в качестве стимула для применения эко-критериев в проведении торгов

Public Procurement Programme (10YFP SPP). Следует включиться в работу международных ассоциаций, занимающихся проблематикой устойчивых государственных закупок, обеспечив постоянное представительство России в них для выполнения рабочих миссий. Такое взаимодействие позволит организовать продуктивный информационный поток, обмен лучшими практиками, привлечёт к совместной работе лучших экспертов от отрасли экологизации закупочной деятельности. Одновременно изучение мирового опыта и взаимодействие с коллегами позволит гармонизировать стандарты и критерии с требованиями, имеющими место в работе зарубежных коллег, ускорит подготовку собственной методической базы и позволит избежать неко- торых ошибок, которые проанализированы нашими партнерами.

Подводя итоги всему вышесказанному, подчеркнем еще раз мощь такого инструмента, как государственное закупки. Государственные закупки - это 14-17\% валового продукта, это политика для поставщика, это стимулы для производства, это пример для всего национального рынка.

Проблемы, которые мы должны решить в первую очередь:

1) анонсировать необходимость работы бюджетных закупщиков с экологическими товарными критериями. Инструментом проведения политического анонса может стать открытое политическое заявление приверженности 
России курсу устойчивой/зелёной/цикличной экономики, включение посыла в программные документы, знаковые публичные выступления Президента и Председателя Правительства РФ, ответственных министерств и ведомств;

2) подготовить стартовые специализированные учебные курсы на базе федерального Министерства природных ресурсов и экологии, а также Правительства Москвы (с последующим этапным распространением этой деятельности на регионы, с включением администраций и университетских площадок). К проведению этой работы, формированию учебных стандартов и планов, лекторию следует привлечь лучших отечественных и зарубежных профессионалов;

3) наладить эффективную систему обучения закупщиков и поставщиков, связанную с экологизацией государственных закупок, подготовив блок соответствующих образовательных, методических и практических пособий;

4) обязать чиновников высшего уровня пройти кратковременное обучение по тематике цикличной экономики (+), ступенчато переводя процесс на менеджмент разных уровней;

5) поддержать создание специализированной государственной и межгосударственной научно-технологической структуры, которой поручить в рамках Национального проекта «Экология»+ и межгосударственного финансирования (интеграция) формирование отраслевых критериев продукции в России, Евразийском регионе и содружестве стран-членов БРИКС;

6) заняться анализом эффективности работы сертифицирующих по экологическим стандартам организаций, организовав электронный ресурс экологической сертификации, освещающий учет, отчетность и текущую работу по сертификации продукции. На этом портале должна аккумулироваться и храниться информация по сертификации продукции с описанием этапов и сроков проведения ступенчатого процесса с документальным и визуальным подтверждением; портал должен использовать технологию подтвержденного протокола и обеспечить доступ зарегистрированных в системе (авторизованных) пользователей к получению информации. Сюда же целесообразно подключить систему «Консультант GZ” и установить прямую электронную связь с Каталогом экологичной продукции. Это поможет сертифицированным продуктам автоматически пополнять ряды специализированного Каталога, откуда черпа- ют подробную информацию заинтересованные стороны: закупщики, потребители и другие;

7) формирование Каталога экологичной продукции поручить Правительству РФ, точнее, Министерству природных ресурсов и экологии, также включив эту задачу структурной единицей в Национальный проект «Экология»+; с учетом того, что финансовая структура проекта пересматривается, нужно найти место в проекте тематике эко-критериев и государственным «зеленым» закупкам. Каталог должен формироваться постепенно, с претензией не на количество, а на качество информации, к тому же, его наполнение должно соответствовать процессу роста рынка экологичных товаров, а это, как известно, в первую очередь, политический вопрос;

8) всю информацию, касающуюся устойчивых/зеленых государственных закупок, разместить на едином портале «GPP_Russia»/ «Россия Зеленые_государственные_закупки», включив туда политические, законодательные и организационные аспекты профильной деятельности, научную, методическую и новостную информацию, развивая и дополняя его полезными звеньями;

9) имеющийся практический национальный задел в области экологичного государственного заказа следует также осветить на специализированном портале (см. п.6 + 8), выделив блок «лучших отечественных практик, технологий и критериев», сопроводив его «разбором полётов», выделив позитивный долговременный опыт как пример и проанализировав ошибки;

10) создать и анонсировать публичный рейтинг «зелёных» компаний, соблюдающих принципы социальной ответственности бизнеса, работающих с устойчивой отчетностью, имеющих сертификаты международных систем стандартизации ИСО, внедряющих наилучшие доступные технологии и безотходное производство. Для рационального действия данный ресурс лучше всего представить в балансе: «зеленый рейтинг» противопоставить «чёрному рейтингу», чтобы были стимулы у компаний избегать статуса худших (чёрный список - список компаний, производство которых наносит большой вред окружающей среде) и стремиться попасть в престижный зелёный список. Такое ранжирование найдет своих противников и может вызвать активные протестные действия, но пиар активизирует деятельность необычайно быстро, так что данный инструментарий представляется 
чрезвычайно полезным в ускорении реального движения к устойчивому развитию. Предлагаем отдать на разработку данный ресурс технологам от IT и блокчейна, оставив смысловую часть формирования принципов рейтинга лучшим профессионалам от экологии, зеленой экономики и социальной ответственности;

11) федеральный экологический портал должен дать подробную информацию для изучения по case-study, наполнение которой надо продумать с целью получения максимальной эффективности по результату от приведенных примеров;

12) федеральные законы о закупках следует доработать на предмет более четких рекомендаций по использованию экологических критериев, но, учитывая принцип добровольности их применения, следует поработать над данной темой очень тщательно, привлекая лучших международных юристов и практиков от закупки;

13) провести экспериментальные торги (продумав направление), определив простые экологические критерии для тендера (заручившись невозражением ФАС), и затем принять к анализу и разбору результаты, осветив полученный опыт в средствах массовой информации (создавая тем самым положительный имидж прецеденту);

14) открыть государственный зеленый ТВ канал, где, помимо просветительских, научных, развлекательных и информационных программ под «зеленым» соусом (общая экологическая тематика по отраслям: туризм, промышленность, сельское хозяйство, культура, спорт, мода и т.д.) сделать блок по зеленым закупкам, ограничен- ный по времени и окупаемый рекламой экологичных товаров;

15) инициировать проведение специализированных грантовых конкурсов и программ, связанных тематикой проведения «зеленых» тендеров;

16) сформировать Экспертный совет по зеленым государственным закупкам с участием представителей науки, бизнеса и общественности.

В процессе создания национального экологичного товарного рынка важно сделать первые шаги, постепенно расширяя круг задач и совершенствуя инструментарий их выполнения. Новое время принесет новые технологии, важно не стоять на месте, а присоединиться к прогрессивному мировому тренду по строительству цикличной экономики и принять лучшие международные практики к изучению и применению, внося свою творческую лепту в созидательный процесс.

Шаг за шагом следует наращивать практический инструментарий для выполнения задач по «озеленению» экономики, создавая условия для безопасной и благоприятной жизни на Земле. Национальная роль России в этом процессе очень важна, так как именно она служит территориальным и политическим мостиком на евроазиатском пространстве. Действуя в сотрудничестве с партнерами и соседями, можно добиться многих позитивных результатов и устойчивые/ зеленые государственные закупки должны сыграть в процессе строительства цикличной экономики ведущую роль.

\section{Библиографический список}

1. Европейский каталог экологичных товаров. Доступ по ссылке: URL/http://ec.europa.eu/ecat/products/en

2. Российский каталог строительных материалов Green Book. Доступ по ссылке: URL/http://greenbook.pro/ catalog/

3. Руководство пользователя ЕСАТ для держателей лицензий. ECAT User Manuals for Licence Holders. Доступ по ссылке: URL/http://ec.europa.eu/environment/ecolabel/eu-ecolabel-for-businesses.html

4. Communication from the Commission to the European Parliament, the Council, the European Economic and Social Committee and the Committee of the Regions Public procurement for a better environment $\{$ SEC(2008) 2124\} \{SEC(2008) 2125\} \{SEC(2008) 2126\}/* COM/2008/0400 final\%. Доступ по ссылке: URL/https://eur-lex. europa.eu/legal-content/EN/TXT/?uri=celex\%3A52008DC0400

5. Пример создания экспертной группы (групп): Открытые стандарты консультативных процедур и координации одобрения критериев. Доступ по ссылке: URL/http://ec.europa.eu/civil_society/consultation_standards/ index_en.htm 